\title{
Moderation and Competence: How a Party's Ideological Position Shapes its Valence Reputation
}

Short title: Moderation and competence

Keywords: ideological position, party competence, conjoint experiment, left-right, valence

Authors:

Robert Johns (rajohn@essex.ac.uk)

Ann-Kristin Kölln (koelln@ps.au.dk)

Department of Government

University of Essex

Department of Political Science

Colchester

Bartholins Allé 7

CO4 3SQ

Building 1340, 231

UK

8000 Aarhus C

Denmark

The data collection was funded by grants from BA/Leverhulme (ref. SG163176) and the Aarhus Universitets Forskningsfond (grant no. 27454). That support is much appreciated. Earlier versions were presented to colleagues in Aarhus University's Political Behavior workshop, the Political Studies Association's Conservatives \& Conservatism specialist group, the Democracy Elections Citizenship unit at the Universitat Autònoma de Barcelona, a panel on 'Electoral and Attitudinal Consequences of Changing Party Positions in Europe' at the Annual Meeting of APSA, and a panel on 'Measuring Political Perceptions' at the Annual Meeting of SISP. We are very grateful to participants and especially discussants for their help and advice. For suggestions and comments outside of workshops and panels, we would like to thank Lawrence Ezrow, Jane Green, Jens Hainmueller, Justin Jackson, Debra Leiter, Jonathan Polk, Rune Stubager, Federico Vegetti, Markus Wagner, and Teppei Yamamoto. We are also grateful to three anonymous reviewers for comments that greatly improved the paper. 


\title{
Moderation and Competence: How a Party's Ideological Position Shapes its Valence Reputation
}

\begin{abstract}
We combine several strands of research from electoral behaviour and party politics to suggest that ideological moderation will boost a party's perceived competence. Less radical parties are seen as readier to compromise, more realistic about what can be achieved, and less prone to simplistic solutions. The results of conjoint experiments with party profiles show that, while an ideological leaning carries no cost, any appreciably left- or right-wing position eroded a party's perceived competence among a representative sample of around 2,000 British citizens. This effect holds when controlling for respondents' ideological proximity to the party in question, and looks to operate through all three of the proposed mechanisms suggested above - especially willingness to compromise. These findings have important implications both for party strategy and for voting research, highlighting a key channel through which ideological moderation yields electoral gains.
\end{abstract}

Replication Materials: The data, code, and any additional materials required to replicate all analyses in this article are available on the American Journal of Political Science Dataverse within the Harvard Dataverse Network, at https://doi.org/10.7910/DVN/PBORGO.

Word count: 9,883 
There is nothing new about the notion that parties must compromise ideologically in order to gain electorally. Studies of party competition and electoral behaviour have repeatedly shown that elections are won in the centre ground (Downs, 1957; Kirchheimer, 1966; Adams and Somer-Topcu 2009; Keman 2011). When parties moderate their left-right position they gain in vote share. This is partly because ideological moderation takes parties closer to voters in general and to the median voter in particular. Yet an additional reason is suggested by a number of real-world cases - for instance, Felipe Gonzalez, Tony Blair, Romano Prodi, Angela Merkel and Fredrik Reinfeldt - who not only steered their parties towards the centre but were seen as offering more credible and effective government than under previous leaders. Tony Blair's 'New Labour' is an instructive example: the party was perceived not only as ideologically moderate but also as more competent across a range of policy areas (Sanders, 1999). The question driving this paper is: are those two related? Were moderation and competence separate cornerstones of the success of parties like New Labour, or did the reputation for competence derive - at least in part - from ideological moderation ${ }^{1}$

There are reasons to suppose the latter. Research on party politics and electoral behaviour suggests that more ideologically moderate parties might be seen as more competent because they are readier to compromise (e.g. Adams et al. 2006; Fortunato 2019; Katz and Mair 2009, 2018), more realistic in what can be achieved (e.g. Katz and Mair 2009; Lipset, 1964; Wagner and Zeglovits 2014), and less simplistic in their political solutions (e.g. Bischof and Senninger 2018; Canovan, 1999; Marx and Nguyen 2018). Yet the direct evidence of a relationship between ideological moderation and competence is so far confined to anecdotes and examples, with too many other variables in play to allow confident causal inference. What we know from the literature on issue

\footnotetext{
${ }^{1}$ While the term 'moderation' often implies a process, we also use it to refer to a state - that is, the state of being in centrist ideological territory.
} 
ownership and spatial voting is that a citizen's ideological proximity to a party is a source of perceived party competence as well as vote choice (e.g. Bellucci 2006; Sanders et al. 2011; Stubager and Slothuus 2013; Zakharova and Warwick 2014). But there has been no systematic test of the relationship between a party's ideological position and its perceived competence. This represents something of a dereliction of duty among researchers given the strategic importance of the question. If parties' ideological manoeuvrings have knock-on effects on their perceived competence, then the electoral calculation changes. There is therefore both academic and practical interest in putting our question to a rigorous test.

In this paper, we argue that ideological moderation positively affects perceived party competence - and does so because more moderate parties are seen as more willing to compromise, more realistic in what can and cannot be achieved, and more complex in their proposed political solutions. Our test of these hypotheses comes via a conjoint experiment embedded in an online survey fielded on a representative sample $(\mathrm{N}=1,999)$ of the British electorate. Various features of hypothetical parties are manipulated, including their left-right position, and we observed the effects on perceived competence. The results strongly support our hypothesis. Parties described as 'fairly' or 'very' left or right wing in political outlook were respectively 8 and 15 percentage points less likely to be deemed more competent than parties in the centre. Moreover, these results persist when we control for people's own ideological position, which means that it is truly the party's ideological position that influences competence ratings and not ideological proximity. Our results also provide evidence of the channels through which ideology might affect competence, moderation being associated with realism, a recognition of the complexity of politics, and above all greater willingness to compromise. The findings speak to our understanding of both spatial and valence voting, and are also important for studies of party politics. 


\section{Ideological moderation and competence}

Translated into the jargon of electoral behaviour, our core question is: are valence evaluations shaped by positional considerations? Competence is at the heart of the valence or 'performance politics' tradition of explaining electoral behaviour. For example, Clarke et al. $(2004,2009)$ define competence in terms of whether parties are seen as likely to deliver on agreed goals. Similarly, Green and Jennings (2017) talk about how well a party is seen as handling or would be trusted to handle one or more policy areas. In any particular area, that trust would have its own specific drivers, notably the priority the party gives to that policy area and the policies it espouses (e.g. Walgrave, Tresch and Lefevere 2015; Stubager and Slothuus 2013). However, as Green and Jennings demonstrate, parties also acquire a reputation for general competence (or incompetence). Voters have an overall impression of how well a party can handle issues as they arise - or, put crudely, how well it would run the country. There is a very large weight of evidence that this general reputation matters electorally (e.g. Clarke et al. 2004, 2009; Bellucci 2006; Clark 2009; Bélanger and Nadeau 2014; Green and Jennings 2017).

There is rather less evidence on the sources of this reputation and none at all on our central question about whether ideological position affects general competence. This may be because ideology and valence were traditionally seen as rival explanations of voting behaviour. Yet they are now recognised to interact in a range of ways. One important line of research highlights the possibility that parties' or candidates' ideological positions may, in fact, be strategic consequences of their pre-existing valence reputations. Candidates with a valence advantage have an incentive to locate close to the median voter in their district, seeking to reduce the salience of ideology and thus to profit fully from that advantage. This result is derived theoretically by Groseclose (2001; see also Adams and Merrill 2009; Schofield 2004; Aragones and Palfrey 2004; Serra 2010) and has now been supported by a range of studies, with valence advantage shown to predict moderation among congressional candidates (Stone and Simas 2010; Adams et al. 2011) and parties in post- 
communist Europe by Somer-Topcu (2007) - although Clark (2014) reports the reverse result among Western European parties.

This strategy of policy moderation when enjoying a valence advantage appears vindicated by Franchino and Zucchini's (2015) finding that competence perceptions matter more when voters consider a candidate close to them ideologically. Moving from candidates to parties, Green (2007) makes a parallel claim, showing that valence matters more when parties have converged since there is less ideological basis for choice. That debate is ongoing, with subsequent studies indicating that valence matters more when parties are polarised, since this magnifies differences on a range of dimensions - including competence (Pardos-Prado 2012; Clark and Leiter 2014; Vegetti 2014).

In sum, existing studies highlight that a party or candidate's ideological position is likely to respond to valence perceptions and may also condition the electoral importance of those perceptions. Neither of these is inconsistent with our claim that ideological positions directly affect valence evaluations. Indeed, it is entirely possible that causality runs both ways here, with parties reacting ideologically to their valence reputations while voters draw valence conclusions from parties' ideological locations. The question for present purposes is: does existing research provide any evidence that, as Vegetti suggests, "voters may evaluate a party as more competent because of its position" (2014: 232, emphasis in original)?

There is some - but it concerns a party's position relative to the voter, rather than its position as such. Several studies show that those closer to a party (Bellucci 2006; Sanders et al. 2011), or at least on the same side of the ideological spectrum (Zakharova and Warwick 2014), tend to see it as more competent. Since a voter's ideological position is, at least in part, an expression of her view about how society is best run, we would naturally expect an effect of proximity on perceived competence. The more distant a party lies from a voter, the less likely she is to believe it willing or able to deliver her political objectives (Sanders et al. 2011). Yet there is an important distinction between proximity and position. It is not surprising that people with a given ideological standpoint 
regard a party sharing that standpoint as more likely to deliver preferred outcomes. Our contention is different. We also expect an effect of position on perceived competence, with voters regarding more centrist or moderate parties as more likely to deliver - period. Imagine a voter on the right of the spectrum. She is liable to regard right-wing parties as more competent than leftwing parties; our point is that, if comparing two right-wing parties, she is inclined to regard the more moderate one as more competent. ${ }^{2}$ She may even suspect that a centre-left party is more competent than an extreme or radical right-wing party. Proximity matters, but so does position.

It is important to differentiate those two effects here because, at the aggregate level, proximity alone could generate the expected pattern. If voters are disproportionately clustered in the centreground, and they regard parties closer to them as more competent, then more centrist parties will be rated on average as more competent. Similarly, if candidates who are already seen as more competent then choose moderate positions, we would again expect aggregate data to show an association between moderation and competence - but it would be driven by the latter. Our claim and test are for an individual-level effect of perceived moderation on perceived competence: the closer a party lies to the ideological centre, the more likely is a voter to rate it as competentholding constant her proximity to that party $(\mathrm{H} 1)$.

One basis for this hypothesis follows from the argument about proximity made earlier and is spelled out by Sanders et al.: "Parties viewed as closer than their competitors to voters in spatial terms are more likely to be judged as credible vehicles for achieving widely shared policy goals" (2011: 312). If most voters are in or around the centre ground, then that is where the widely shared objectives lie, and so voters are likely to see more centrist parties as more competent.

\footnotetext{
${ }^{2}$ There is an echo here of the directional model of ideological voting (Rabinowitz and McDonald, 1989; Merrill and Grofman, 1997) whereby voters give precedence to their own side of the ideological divide but, within that side, their assessments are based on more than just proximity.
} 
However, there are different arguments, unrelated to proximity and not requiring assumptions about the ideological distribution of voters. These are instead driven by the notion that more moderate parties are readier to accept the constraints of the existing system - and hence better at working within it. Drawing on several distinct strands of party politics research, we specify three potential links between our main independent and dependent variable.

First, we anticipate that more ideologically moderate parties may be seen as more competent because they are more willing to compromise (H2a). According to Katz and Mair's (1995 2009 2018) famous thesis, for example, cartel parties were distinguished by having undertaken a process of "depoliticization" which "made it that much easier for parties to cooperate" (2009: 756). By contrast, more extreme parties typically adopt a policy-seeking rather than a vote-seeking strategy and are naturally less willing to give ground on policy (Strøm, 1990; Adams et al. 2006; Fortunato 2019). Adams et al. argue that "niche parties' activists are strongly policy oriented and are therefore highly resistant to ideological 'compromises' in their party's policies" and that this "may tarnish the party's standing along such 'valence' dimensions of voter evaluation as competence and reliability" (2006: 515; see also Fortunato 2019: 63). This is not only about willingness but also availability: ideologically extreme parties have fewer options to reach out to others and to negotiate various interests. Although the importance of compromise is particularly clear in a multiparty system with coalition governments, we expect $\mathrm{H} 2 \mathrm{a}$ to apply in majoritarian contexts too. Policymaking - especially successful policymaking - is always partly a matter of negotiating with various interests and stakeholders.

Second, we hypothesise that more ideologically moderate parties may be seen as more competent because they are seen as more realistic in what can and cannot be achieved (H2b). Driving this is the idea that the centre ground is not so much a different ideological location as a less ideological location. Both the cartel party and Kirchheimer's (1966) catch-all party are characterised by a more centrist profile that de-emphasises ideology (see also Allen 2009). Centrist 
parties can focus on what works, while strongly left- or right-wing parties have also to be concerned with what is ideologically pure. In support of that, moderate parties have been described as competing on a limited number of issues "in the name of 'realism"' (Katz and Mair 2009: 758; 2018: 16) and with a "pragmatic orientation" (Krouwel 2003: 30; Lipset, 1964). In a series of cognitive interviews exploring Austrian voters' understandings of party competence, Wagner and Zeglovits also find that parties "were seen as competent when they set realistically achievable goals that could actually be implemented, and they were incompetent when they made promises that they knew would be impossible to realize" (2014: 284).

A third potential mechanism relates to policy complexity. The straightforwardness of the solutions proposed by the radical left and right is one reason why both are often associated with populism. Their aim is to simplify the political discourse (Bischof and Senninger 2018; Moffitt and Tormey 2014; Oliver and Rahn 2016) and thus to gain rhetorical appeal. Populist parties "pride themselves on simplicity and directness" not only in their style but also in their "political analyses and proposed solutions" (Canovan, 1999: 5). One of the intended messages is that "politics is not all that complicated" (Marx and Nguyen 2018: 923). The flipside of such messages is that they may be seen as ignoring the complex realities of governing a modern state. We therefore expect that more ideologically moderate parties may be seen as more competent because their proposed political solutions are seen as less simple $(\mathrm{H} 2 \mathrm{c})$. Technocratic governments illustrate the link well: their twin selling points are a grasp of the intricacies and difficulties of governing and a nonideological concern with what works.

\section{Data and methods}

\section{Design and data}

We test our hypotheses experimentally. This approach's advantage in terms of internal validity are all the more important because of those studies reviewed above (e.g. Stone and Simas 2010; Clark 
2014) which suggest strategic ideological shifts in response to valence-related considerations. Any positive association between moderation and competence in observational data is thus ambiguous: it may be that voters may see more moderate parties as more competent or it may be that more competent parties moderated their positions. We therefore move beyond this previous research not only in positing that moderation shapes perceptions of competence but also in deploying a research design that can eliminate reverse causality.

The specific design used is choice-based conjoint experiments embedded in a representative sample survey of the British electorate. Conjoint experiments are designed to separate the causal effects of several aspects of a treatment. In our paired conjoint design, several features of two hypothetical parties, including their ideological positions, are manipulated and we observe the effect of those manipulations on respondents' choice of which is the most competent. The use of hypothetical parties means that respondents' ratings are much less influenced by preferences among real-world parties. Meanwhile, the method of analysing conjoint experiments presented by Hainmueller, Hopkins and Yamamoto (2014) allows simultaneous estimation of the effects of multiple attributes of each party, even if any specific combination of attributes is seen by just a handful of respondents. This means that we can test whether ideological position has an effect even when respondents are given a number of other cues about a party's likely competence. Conjoint experiments are now widely used in political science, recent studies examining, for example, attitudes towards different kinds of immigrants, political candidates and Members of Parliament (Franchino and Zuccini 2015; Hainmueller, Hangartner and Yamamoto 2015; Vivyan and Wagner 2015 2016). Nevertheless, this to our knowledge is the first time that the conjoint design has been used to present profiles of political parties.

The paired conjoint design - that is, two party profiles compared side by side as opposed to each party being considered in turn - is the variant shown by Hainmueller et al. (2015) to score highest in terms of respondent effort and external validity. It also has obvious applicability to the 
electoral context in which parties are indeed compared and contrasted. Figure 1 illustrates the nature of the choice task in this design. Each profile included the party's 'Political outlook' on a seven-point left-right spectrum, alongside seven other pieces of information about the party. ${ }^{3}$ Levels of all eight attributes were randomly assigned to the party profile tables from predefined lists (see Table A1 on pages 2-3 of the appendix). As well as offering respondents many other bases for judging competence, the seven additional attributes also reduce the danger of respondents trying to guess which real-world party is being described (since any profile is likely to contain information inconsistent with that first guess). They also provide useful benchmarks against which to judge the size of any effect of moderation on competence.

\section{[Figure 1 about here]}

Respondents undertook two such choice tasks. In each case, having ranked and rated the parties' competence $(\mathrm{H} 1)$, they were then asked three questions about each party relevant for testing the mechanisms through which ideological position might have influenced those ratings $(\mathrm{H} 2 \mathrm{a}-\mathrm{H} 2 \mathrm{c})$. The second choice task was followed by measures of other variables of interest, notably left-right self-placement, party identification and political engagement. The full questionnaire is provided on pp. 6-8 of the appendix.

Our data were collected between 12 and 24 July 2018 from a non-probability sample of 1,999 British adults. Fieldwork for this standalone survey was conducted by Deltapoll. Like other internet survey agencies (such as YouGov, whose methodology it follows quite closely), Deltapoll maintains a large panel of subscribers from which it samples afresh for each data collection, paying small

\footnotetext{
3 'Leader name' was a random selection from 40 names 20 female and 20 male. (These were chosen from a longer list pre-tested via Prolific Academic on a small [N=104] sample of British adults to avoid distinct age or social class connotations.) For analysis, we collapsed the variable into a male/female condition.
} 
incentives to respondents to complete the survey. The agency uses quota sampling and reweighting to generate samples from this pool of potential respondents that are nationally representative with respect to age, gender, educational attainment, social grade, region, and vote in the most recent (2017) general election. Following the advice of Miratrix, Sekhon, Theodoris and Campos (2018: 275), we do not weight the data for the experimental analysis. With two choice tasks per respondents, our dataset comprises almost 4,000 paired comparisons and 8,000 evaluated party profiles - the latter serving as units of analysis for this study.

\section{Measures}

Our primary dependent variable is Profile Choice: that is, the respondent's answer to the question "which party do you think would be generally the most competent, regardless of how much you agree with each party". As also shown in Figure 1, we also asked respondents to rate each of the party profiles on a scale from 0 ('not at all competent') to 6 ('very competent'). We expect results to be similar across the two measures but will use the forced choice as our primary dependent variable for testing H1. Previous conjoint analyses have shown profile choice questions to yield more reliable data than profile ratings (Hainmueller et al. 2015). ${ }^{4}$

Two points about these measures, designed specifically for this study, are worth noting. First, we depart from previous studies which have mostly equated party competence with issue competence and have therefore used issue-specific measures - typically of the form "which party is best at handling [issue]?" (e.g. Bellucci 2006; Green and Jennings 2011; Pardos-Prado 2012; Walgrave et al. 2015; Stubager 2018). Green and Jennings share our conceptual interest in a

\footnotetext{
${ }^{4}$ This chimes with survey methodologists' findings that ranking questions often outperform rating questions: respondents often satisfice by giving two objects the same rating on a scale yet, if prompted into the cognitive effort of choosing between them, can do so reliably and validly (Krosnick, 1999).
} 
measure of generalized or 'macro-competence' but measure it indirectly via the "common variation in public evaluations of competence across a range of [specific] issues" (2011: 319; see also Green and Jennings 2017). We aim instead for an explicitly general measure rather than asking about a series of issues. This is not simply because there are advantages in directness and brevity but also because, as indicated in Wagner and Zeglovits's (2014: 284) cognitive interviews referred to earlier, general competence may well be more than the sum of its issue-specific parts. Second, we follow Wagner and Zeglovits's suggestions to refer directly to competence in survey questions and to be explicit about its distinctness from parties' positions or priorities. A similar recommendation is made by Walgrave et al. (2016), who tested four different measures of issue competence and find that the addition of "regardless of whether you agree with the party or not" best decouples the concept from positional agreement with the party. By adding this to our own measure, we help to disentangle the effects of proximity and position on perceived competence.

To measure our main independent variable of ideological moderation (on either side of the political spectrum), we folded the seven-point party ideology variable around its midpoint to create a four-category moderation-extremity variable. Measuring a party's distance from the ideological centre, it is an ordinal variable ranging from 0 to 3.

To test the hypotheses about potential mechanisms, we translated the three core concepts of compromise, realism and complexity into three questions:

i) "Some parties are unwilling to compromise, believing that they should stick to their principles. Others are more willing, believing that co-operation and compromise are sometimes necessary to get things done. How would you rate the two parties on this scale of willingness to compromise?" [0 'not at all willing' - 6 'very willing'],

ii) "How realistic you think each party would be about what can and cannot be achieved?" [0 not at all realistic' - 6 'very realistic'], 
iii) "Some parties put forward simple solutions to problems, while others think that things are more complicated. How would you rate the likely approaches and proposals of the two parties on this scale?" [0 'very simple' - 6 'very complex'].

\section{Estimation}

To estimate effects, we use the cjoint package in R (see Barari et al. 2017) and we cluster standard errors by respondent. We estimate the effects of all levels across the eight party attributes on people's competence ratings. Hainmueller et al. define the average marginal component effect, or AMCE, as the marginal effect of an attribute averaged over the joint distribution of the remaining attributes. It means that the AMCE "equals the increase in the population probability that a profile would be chosen" (2014: 10-11). The AMCE is obtained by regressing the dependent variable on dummy variables for all levels, except for one per party attribute to serve as the baseline. We can thus formally define party competence judgements based on all party attributes as taking the following form:

$$
P=\alpha+\beta_{1} X_{1}+\beta_{2} X_{2}+\ldots \beta_{n} X_{n}+\beta_{c} C+\beta_{1 c} X_{1} C+\beta_{2 c} X_{2} C+\beta_{n c} X_{n} C+\varepsilon,
$$

where $P$ are respondents' party competence judgements and $X_{1}, X_{2}$ and $X_{n}$ are different levels of the eight party attributes, amongst others parties' levels of ideological moderation. The equation also includes interactions of vector $\mathrm{C}$ with every party attribute. This vector $\mathrm{C}$ contains information on respondents' self-placement on the left-right scale. This control ensures that the main effect of moderation captures the impact of a party's position rather than its match with the respondent's. To test our main hypothesis, we use equation (1) and estimate the AMCE for moderation and all other party characteristics on Profile Choice (H1).

$\mathrm{H} 2 \mathrm{a}-\mathrm{H} 2 \mathrm{c}$ are hypotheses about the potential mechanisms through which moderation might influence competence. We emphasise the word 'potential' because, since the survey questions about compromise, realism and complexity were asked post-treatment and there was no attempt 
to manipulate these variables explicitly and separately, this is not a mediation analysis (see Bullock and Ha 2011). What can be subject to unbiased test are the hypotheses that a party's ideological moderation should also lead to it being perceived as more willing to compromise, more realistic in what can and cannot be achieved, and more complex in its proposed political solutions. Estimate the AMCE of moderation on the three mechanism variables is thus a key first stage of identifying the characteristics of a party cued by its ideological stance. We do this using equation (1) again but substituting, one at a time, the dependent variable of Profile Choice with the variables of Compromise, Realism, and Complexity. For the analysis, we rescaled the seven-point scale measures of these three variables to range between 0 and 1.

\section{Results}

The first task is to test our central conjecture that more moderate parties are seen as more competent. This comes via a conjoint analysis estimating the effects of moderation alongside all party characteristics on general competence, using the variable that forced respondents to choose which party they deemed more competent (Profile Choice). The results generated are Average Marginal Component Effects (AMCE). These report, for a given level of each attribute of a party, the impact of a respondent seeing that level rather than a chosen baseline on the probability that that party was chosen as the most competent. For our ideological moderation variable, the baseline is 'centre' and so we anticipate progressively more negative AMCEs - the further a party is from that ideological centre, the lower the probability that it is chosen as most competent.

\section{[Figure 2 about here]}

Figure 2 shows these AMCEs, along with 95\% confidence intervals, for the full analysis. The labels in bold highlight our main independent variable and the results provide clear-cut support for our core hypothesis. Parties seen as 'very' or 'fairly' left or right wing are significantly less likely to be chosen as more competent than those at the ideological centre, all other things remaining 
the same. The first column in Table 1 documents the precise effect sizes and their standard errors, all based on the full model. If a party was described as 'fairly' left or right (labelled centre $+/-2$ in Figure 2), this reduced the probability of its winning the competence contest (relative to a centre party) by 0.08 , or eight percentage points. The corresponding difference for parties described as 'very left wing' or 'very right wing' is 15 percentage points. This is no small effect. And it is obtained from a model including an interaction term between a respondent's self-placement and that of the party in question. Plainly, voters consider a party's position and not only its proximity to them when assessing its competence..$^{5}$

\section{[Table 1 about here]}

Interestingly, however, the very slightly negative effect of being 'centre left' or 'centre right' is nowhere near significant. There is little or no competence penalty for an ideological leaning; it is when ideological positions become more pronounced that there are valence implications for a party. One interpretation is that the effect of extremity on (in)competence is non-linear. Another is that, while there are signs of a linear effect, it does not kick in straight away because parties one point from the centre - defined in the profiles as 'centre left' and 'centre right' - may not be seen as any less moderate than those right in the centre. We return to this distinction in the conclusion.

While our main interest is in the effects of ideological position, it is worth at least noting some of the other significant predictors in Figure 2. Party competence evaluations decrease more or less monotonically the longer the party has been absent from power (in Government). This raises the

\footnotetext{
${ }^{5}$ These results are largely robust if we use the competence ratings (Profile Rating) rather than the forced-choice dependent variable. The pattern, shown in Figure A1 (page 4 of the appendix), is very similar and the core result - that parties with a noticeable ideological slant are seen as less competent - holds. While there are methodological reasons to place more faith in the forcedchoice results, the consistency of that core result is reassuring.
} 
interesting possibility of a 'cost of not ruling', voters doubting the competence of inexperienced parties while inferring that parties voted into office (especially in a majoritarian context like the UK) must have been widely deemed competent by others. ${ }^{6}$ Parallel inference might drive the effects of party size as measured by vote share in the polls - 'if a party is that popular, it must be reasonably competent' - although the effects for party membership suggest that small parties face doubts more generally about their competence. Finally, and unsurprisingly, there are clear effects of the valence characteristic of party unity (see Andersen and Evans 2003; Greene and Haber 2015). Parties described as 'deeply divided' were markedly less likely to be seen as competent. Yet perhaps the most striking feature of the party unity results is that, even though this attribute is ostensibly much less neutral than our main 'political outlook' variable, the latter has a comparable effect - at least when it comes to parties described as 'very' left or right wing. Overall, Figure 2 suggests that a pronounced ideological stance should be considered one of the more important cues for the competence of a party.

Effect size can be judged in absolute as well as relative terms. A relevant question is whether real-world parties are widely seen as 'fairly' or 'very' left or right wing. It is a pertinent question in the majoritarian British context with the centripetal pressures in its party system. However, it is far from unusual for British voters to see parties as occupying very left- or right-wing positions. In the May-June 2017 wave of the British Election Study (BES) internet panel, respondents were asked to place all the main parties on a 0-10 left-right scale. Of those (around four in five) who could place each party, $40 \%$ placed the Labour Party at 0 or 1 and $41 \%$ of respondents placed the Conservatives at 9 or 10 . (Fully 52\% placed the strongly pro-Brexit UKIP at the rightmost extreme on the scale.) Moreover, these widespread perceptions of extremity are

\footnotetext{
${ }^{6}$ This does not contradict the notion that incumbent parties face 'costs of ruling' (Nannestad and Paldam, 1994) as the challenges and problems mount over their terms of office.
} 
not merely the result of projection whereby those on one side of the ideological scale paint parties on the other side as extremists. Even among respondents placing themselves to the left of the midpoint, $24 \%$ located Labour at 0 or 1 ; among those to the right, $27 \%$ placed the Conservatives at 9 or 10 . According to our experimental results, then, these parties will have a weakened valence standing even among their natural supporters.

Moreover, the core finding goes beyond extremity. Even 'fairly' left- or right-wing parties suffered a significant dent (of eight percentage points) in their likelihood of being deemed most competent. That AMCE is comparable with those of important characteristics like having rarely if ever been in office, or being small in size (polling at 10\%). This is a noticeable effect on competence that falls well within the 'normal' real-world range of party ideological positions. According to British Election Study survey data, the proportion of the electorate deeming the Conservatives 'capable of strong government' declined from 74\% to 47\% between the 2015 and 2017 elections. While there will of course be multiple reasons for this, our results pinpoint their drift to the ideological right in the eyes of many voters as one causal factor.

Next, we are interested in the potential mechanisms through which party ideology might shape competence ratings $(\mathrm{H} 2 \mathrm{a}-\mathrm{H} 2 \mathrm{c})$. As noted, since our design did not permit an unbiased mediation analysis, we report here the first stage of a mechanism test. Figure 3 summarises the results of the effects of moderation with the dependent variables now being respondents' rating of parties' willingness to compromise, realism about what can be achieved, and complexity of proposals. The precise effect sizes are shown in Table 2 and are based on the full model, which again includes an interaction between a respondent's ideological self-placement and that of the party in question. There is potential for all three variables to act as mechanisms as hypothesized, since all three show roughly the same pattern of effects as on the ultimate dependent variable of competence. It is for compromise that the effect sizes are the largest. Along that variable rescaled to 0-1, 'fairly' or 'very' left- or right-wing parties are rated respectively 0.05 and 0.08 points lower on perceived 
willingness to compromise than the baseline 'centre' party. Willingness to compromise is the only one of the three that registers a statistically significant effect even among parties just one point from the ideological centre; the other two show just the same pattern of effects - with 'fairly' and 'very' left- or right-wing parties rating significantly lower - as with competence.

[Figure 3 about here]

\section{[Table 2 about here]}

We run three robustness checks to test the sensitivity of our core finding. The first and most important of these examines whether and how the effects of party position depend on the respondents' own ideological positioning. The inclusion of an interaction between party and respondent placement ensures that Figure 2 reports an effect of moderation that is distinct from that of proximity. It quells any suspicion that more centrist parties were preferred on competence merely because that is where most voters lie. But proximity will matter too, of course; moreover, the pull of ideological proximity over ideological moderation is likely to be stronger for those citizens further from the centre ground themselves. We therefore report the effects of party position on competence for respondents at all seven points along the ideological scale. The key difference between this and the previous analysis is that, where respondents reported an ideological slant, we consider only their reactions to parties on that same ideological side. This enables us to focus on what might be thought of as the 'acid test' comparisons: do, for example, 'fairly left-wing' respondents regard 'centre left' parties as more competent than 'very left' parties? Figure 4 is split into four panels, A to D, reporting in turn results for subgroups of respondents depending on their ideological self-placement on the seven-point left-right scale. ${ }^{7}$

\footnotetext{
${ }^{7}$ The confidence intervals are markedly wider than in Figure 2 and differ by subgroup given that each analysis is based on an ideological subset of the sample. The small number of respondents describing themselves as 'very' left $(\mathrm{N}=80)$ or right wing $(\mathrm{N}=37)$, coupled with the fact that some
} 
The effect of proximity is clear: ratings improve relative to the base category of centre parties as we move through the panels and respondents' own ideological leanings become more pronounced. Panel $\mathrm{C}$ shows that 'fairly left' voters regard all three left-oriented parties as more competent than centre parties, and the same is true on the right. Our point is not to dispute that proximity matters, however. The key question here is whether moderation boosts competence when holding proximity constant. And the answer is that it usually does (even if the subsamples are sometimes too small to make the key differences statistically significant). In Panel B, centreleft respondents' top ranking is for centre-left parties as most competent but, if the comparison is between a centre and a fairly left party, they regard the more moderate option as the more competent. The same is true on the right. The effect of moderation is also visible in Panel C. 'Fairly' left- or right-wing respondents give more credit for competence to parties one point to their ideological inside than parties one point to their outside. Even 'very' left-wing voters (see Panel D), who give very short shrift to pure centre parties, show the same tendency to regard centre-left parties as at least as competent as more proximate left-wing options. Note that the results are entirely and oddly different for very right-wing voters, whose preferences suggest concern only with moderation and not with proximity, but the small numbers in this case argue against reading much into that pattern.

\section{[Figure 4 about here]}

In sum, this first robustness test shows that there is a clear tendency for voters to attribute competence to parties on their ideological side, but there is also a clear moderation effect and one that is not confined to centrist voters. This helps to account for the overall pattern in Figure 2 whereby centre-left or centre-right parties were not seen as significantly less competent than pure

of their assessments will be of parties on the other ideological side and hence not included in this analysis, means that the results in Panel $\mathrm{D}$ should be interpreted with particular caution. 
centre parties. That null finding conceals signs of two contrasting effects cancelling out. For centrist voters (Panel A), the valence costs of ideological position seem to kick in even for parties just one point from the centre. However, because left- and right-wing respondents - even those who only lean in that direction - give a clear competence bonus to parties on their ideological side, they rate centre-left and centre-right options as more competent than those in the pure centre.

A second robustness test concerns another likely source of individual-level heterogeneity in treatment effects: political sophistication. As numerous scholars from Converse (1964) onwards have shown, understanding of the terms 'left' and 'right' is the preserve of a minority of the most politically attentive. This fair point applies to any ideology-driven account of public opinion or electoral behaviour: its explanatory power is limited because so is the reach of such thinking in the electorate. While not undermining our logic here, this suggests that the anticipated patterns will be muted for the less ideologically conversant. To test this hypothesis, we used the following measure of self-reported understanding: "Some people use the terms 'left' and 'right' very often and understand them well. Others are a bit less sure about the meaning of left and right. How sure are you on a scale from $0=$ 'very unsure' to $6=$ 'very sure'?". To simplify presentation, respondents were split into two groups that we refer to as 'low' and 'high' on ideological understanding: the $38 \%$ scoring below the median value of 4 and the remainder who scored 4 or above. We interacted this dummy variable with all party attributes in the conjoint table (Figure A2 on page 4 of the appendix). The results show that the effect of the 'political outlook' attribute is indeed more clearcut for those reporting themselves surer about what left-right means (right panel). This bolsters our claim that an ideological calculation lies behind that effect. However, even those with a looser grasp on left-right (middle panel) are at least somewhat responsive to this manipulation. A label like 'very' left or right wing appears to ring valence alarm bells throughout the electorate.

Finally, we examine whether the effects of moderation on competence are different for leftand right-wing parties. There are grounds to suspect such asymmetry. One such is the overlap 
between moderation and conservatism. A readiness to compromise, a pragmatic focus on what works rather than ideological purity, and a willingness to work within the existing system rather than attempting risky overhauls - these are all characteristics of at least some strands of conservative thought (Vannatta 2014). Moreover, according to Quinn (2008), while moderation for the left is about a reputation for (economic) competence, for parties on the right it is more about social justice. Both points imply that the relationship between extremity and competence might be stronger on the left. In order to test this conjecture, we re-run the Figure 2 analysis but with the full seven-point 'political outlook' variable. The results show minimal evidence of asymmetry, as shown in Figure A3 (page 5 of the appendix). If anything, parties on the right are more punished for extremity than those on the left, but any differences are not significant. This analysis thus amounts to a further successful robustness test for our main findings. Whichever side of the ideological divide they lie, parties face no competence cost if they are seen as leaning in one ideological direction, but an appreciable cost if they are described as 'fairly' and an even heavier cost if described as 'very' left or right wing.

\section{Conclusion}

This paper began with a simple idea: that, other things remaining the same, voters see parties further from the ideological centre as less competent. This idea, virtually a truism in much everyday political discourse in our British testing-ground, had not been explored - there or elsewhere - in electoral or party politics research. Now it has, and the claim wins strong support from our experimental analysis. While a party leaning to left or right carries no implications for its competence, any more clear-cut ideological stance comes at a valence cost.

The key phrase 'other things remaining the same' drove our choice of an experimental design. It is worth emphasising how many such 'other things' were included in the conjoint experiments. Respondents were provided with information about the age and size of the party, its policy 
priorities, its history in office, the gender of its leader and its state of internal harmony or disharmony. In addition, of course, information about the party's ideological stance enabled respondents to use proximity as a cue. Yet, beyond proximity and all the other factors, ideological position showed through as exerting a clear influence over competence ratings. The link between position and valence is clear in these results.

These findings expand our understanding of the sources of valence evaluations. To date, few existing studies have examined competence evaluations for non-governing parties (for exceptions, see Butt 2006; Clarke et al. 2009). While voters have plenty of direct evidence to judge the competence of governing parties, such as economic performance, frequency and handling of crises, or fulfilment of pledges, judgements about opposition parties are more indirect, more impressionistic and more difficult but nonetheless electorally potent. After all, electoral choice is also about judging whether opposition parties would do better - sometimes in the absence of any recent record in government. According to our results, ideological moderation has a causal effect on competence ratings, holding constant a party's governmental position. This means that next to ideological proximity and the perceived competence of the leader, according to our findings ideological position can be added to that list of means by which voters judge whether a party is capable of competent government. Moreover, this result is not restricted to sophisticated voters. While a detailed understanding of ideology may be a minority pursuit, our breakdown by selfreported understanding of the meaning of left-right suggests that a majority of voters recognises and responds to descriptions like 'very left/right wing'. This has real-world implications given that, as our analysis of BES data shows, mainstream parties are often seen as 'very' left or right wing even by respondents of the same ideological leaning.

Our findings also make an important but nuanced contribution to the literature on parties' ideological positions. We show that a valence penalty is not paid only by those parties far into the ideological fringe. Even parties described as 'fairly' left- or right-wing were judged less competent 
by respondents. By contrast, 'centre left' or 'centre right' parties were regarded as no less competent than 'centre' parties - and, indeed, as more competent than centre parties by respondents with a left- or right-wing leaning of their own. To be on the centre left or the centre right is to be moderate enough. Put another way, when it comes to competence, there is an ideological 'sweet zone' rather than a 'sweet spot'. This is one reason why our results are not inconsistent with the often disappointing electoral showing of centrist parties, whether in Britain or elsewhere. Pure centrism is not a necessary condition for competence. (Nor is it a sufficient condition, as indicated by the results - notably for size and governing experience - from elsewhere in the experiment.) This 'sweet zone' finding is strategically important because there are a number of reasons - to do with attracting more extreme voters (Grofman 2004), keeping activists engaged (Schofield and Sened 2005) and maintaining a clear purpose and image (Karreth et al. 2013) - why parties might be disadvantaged by too centrist a position. The key strategic question that remains, then, is about what a party needs to do in order to be seen as 'centre left' rather than 'fairly leftwing' (or the same on the right). That looks to be moderate enough to avoid any ideology-related valence penalty.

Two points are worth acknowledging about our method and its results. First, we should emphasize that our experiment shows the valence effect of ideological positions, not shifts. Since the latter are also a proven driver of voters' perceptions of parties (e.g. Adams and Somer-Topcu 2009; Ezrow 2005), an obvious and important extension of our findings would be to study the dynamic effects of position-taking on competence ratings. Recent work by Fernandez-Vazquez (2019) highlights that voters doubt the sincerity of parties' shifts towards a more popular position, suggesting that the valence gains from moderation could be limited - and that there may even be costs in terms of credibility and thus competence. Similarly, examining candidates rather than parties, Tomz and van Houweling (2010) show that those reported to have changed position are regarded not only as less honest but also as less likely to provide strong leadership - a trait 
obviously related to competence. This said, the shifts of real-world parties are accompanied by rhetorical justifications, one of which might be that a more centrist approach will make them a more competent government. This was a successful strategy for several of the examples listed at the beginning of the article. The effects of ideological shifts on perceived competence are liable to be complex and contingent - reinforcing the need for research in that area.

Second, it is inevitably difficult in an experimental design - especially one based on hypothetical parties - to capture the real-world basis on which voters judge parties and their competence. In that real world, other things do not remain the same. For instance, we noted earlier the hefty proportion of voters perceiving the Conservative Party as well to the right - yet the party has been the largest in the past three British general elections and governed, albeit mostly in coalition with or supported by a junior partner - since 2010. This is partly because there are other drivers of competence evaluations, such as the leadership on which the party scored well in the first two of those elections, and partly because other factors then disrupt the connection between competence evaluations and electoral performance. We would nonetheless argue that the effects of ideological position are visible in recent elections. If the Conservatives did not suffer electorally in 2017 from being widely perceived as 'fairly' or 'very' right wing, a plausible reason is that few voters saw Labour as more moderate and even fewer saw them as more competent.

That said, the constraints on external validity in experimental studies argues for their combination with observational data. Such combinations could address interesting questions about the generalisability of our main finding. For instance, left-right subsumes both economic and, perhaps increasingly, social or cultural attitudes. It is worth examining whether valence credit is given for moderation on any dimension or is instead particularly associated with economic policy. Then there is the question of generalisability beyond the British context. The lack of leftright asymmetry boosts confidence that the results are not unique to the British context and its 
(economically) more right-wing centre of gravity. However, another difference between Britain and the majority of Western democracies is a majoritarian system in which coalitions are rare and opportunities in government for smaller ideological parties are even rarer. This experiment could usefully be repeated in a multiparty system where the competence of parties across the ideological spectrum is more relevant and better evidenced. Our hypotheses and mechanisms would still apply but the form of the key relationship might well differ. 


\section{References}

Adams, James, Clark, Michael, Ezrow, Lawrence, \& Glasgow, Garrett (2006). Are Niche Parties Fundamentally Different from Mainstream Parties? The Causes and the Electoral Consequences of Western European Parties' Policy Shifts, 1976-1998. American Journal of Political Science, 50(3), 513-529.

Adams, James, \& Merrill III, Samuel (2009). Policy-Seeking Parties in a Parliamentary Democracy with Proportional Representation: A Valence-Uncertainty Model. British Journal of Political Science, 57(1), 539-58.

Adams, James, Merrill III, Samuel, Simas, Elizabeth N., \& Stone, Walter J. (2011). When Candidates Value Good Character: A Spatial Model with Applications to Congressional Elections. Journal of Politics, 73(1), 17-30.

Adams, James, \& Somer-Topcu, Zeynep (2009). Moderate Now, Win Votes Later: The Electoral Consequences of Parties' Policy Shifts in 25 Postwar Democracies. Journal of Politics, 71(2), 678.

Allen, Christopher S. (2009). Empty nets: Social democracy and the "catch-all party thesis" in Germany and Sweden. Party Politics, 15(5), 635-653.

Andersen, Robert and Evans, Geoffrey (2003). Who Blairs Wins? Leadership and Voting in the 2001 Election. British Elections \& Parties Review, 13, 229-47.

Aragones, Enriqueta, \& Palfrey, Thomas R. (2004). The Effect of Candidate Quality on Electoral Equilibrium: An Experimental Study. American Political Science Review, 98(1), 77-90.

Barari, Soubhik, Berwick, Elissa, Hainmueller, Jens, Hopkins, Daniel, Liu, Sean, Strezhnev, Anton, \& Yamamoto, Teppei (2017). Package 'cjoint': AMCE Estimator for Conjoint Experiments. Version 2.0.6. Release date: $2017-11-9$.

Bélanger, Éric, and Nadeau, Richard (2014). Economic Crisis, Party Competence and the Economic Vote. Acta Politica, 49(4), 462-485. 
Bellucci, Paolo (2006). Tracing the Cognitive and Affective Roots of 'Party Competence': Italy and Britain 2001, Electoral Studies, 25, 548-569.

Bischof, Daniel, \& Senninger, Roman (2018). Simple Politics for the People? Complexity in Campaign Messages and Political Knowledge. European Journal of Political Research, 57(2), 473-495.

Bullock, John G., \& Ha, Shang E. (2011). Mediation Analysis Is Harder than It Looks. In James N. Druckman, Donald P. Green, James H. Kuklinski, \& Arthur Lupia (Eds.), Cambridge Handbook of Experimental Political Science (pp. 508-521). Cambridge: Cambridge University Press.

Butt, Sarah (2006). How Voters Evaluate Economic Competence: A Comparison between Parties In and Out of Power. Political Studies, 54(4), 743-766.

Clark, Michael (2014). Understanding Parties' Policy Shifts in Western Europe: The Role of Valence, 1976-2003. British Journal of Political Science, 44(2), 261-86.

Clark, Michael, \& Leiter, Debra (2014). Does the Ideological Dispersion of Parties Mediate the Electoral Impact of Valence? A Cross-National Study of Party Support in Nine Western European Democracies. Comparative Political Studies, 47(2), 171-202.

Clarke, Harold D., Sanders, David, Stewart, Marianne C., \& Whiteley, Paul F. (2004). Political Choice in Britain. Cambridge: Cambridge University Press.

Clarke, Harold D., Sanders, David, Stewart, Marianne C., \& Whiteley, Paul F. (2009). Performance Politics and the British Voter. Cambridge: Cambridge University Press.

Canovan, Margaret (1999). Trust the People! Populism and the Two Faces of democracy. Political Studies, 47(1), 2-16.

Converse, Philip E. (1964). The Nature of Belief Systems in Mass Publics. In Apter, David (ed.), Ideology and Discontent (pp. 206-69). New York: Free Press.

Downs, Anthony (1957). An Economic Theory of Democracy. New York: Harper \& Row. 
Ezrow, Lawrence (2005). Are Moderate Parties Rewarded in Multiparty Systems? A Pooled Analysis of Western European Elections, 1984-1998. European Journal of Political Research, 44(6), 881898.

Fernandez-Vazquez, Pablo (2019). The Credibility of Party Policy Rhetoric: Survey Experimental Evidence. Journal of Politics, 81(1), 309-14.

Fortunato, David (2019). The Electoral Implications of Coalition Policy Making. British Journal of Political Science, 49(1), 59-80.

Franchino, Fabio, \& Zucchini, Francesco (2015). Voting in a Multi-Dimensional Space: A Conjoint Analysis Employing Valence and Ideology Attributes of Candidates. Political Science Research \& Methods, 3(2), 221-241.

Green, Jane (2007). When Voters and Parties Agree: Valence Issues and Party Competition. Political Studies, 55(3), 629-655.

Green, Jane, \& Jennings, Will (2011). Valence as Macro-Competence: An Analysis of Mood in Party Competence Evaluations in Great Britain. British Journal of Political Science, 42(October), 311343.

Green, Jane, \& Jennings, Will (2017). The Politics of Competence: Parties, Public Opinion \& Voters. Cambridge: Cambridge University Press.

Greene, Zachary, \& Haber, Mathias (2015). The Consequences of Appearing Divided: An Analysis of Party Evaluations and Vote Choice. Electoral Studies, 37, 15-27.

Grofman, Bernhard (2004). Downs and Two-Party Convergence. Annual Review of Political Science, 7, 25-46.

Groseclose, Tim (2001). A Model of Candidate Location when One Candidate Has a Valence Advantage. American Journal of Political Science, 45(4), 862-886. 
Hainmueller, Jens, Hopkins, Daniel J., \& Yamamoto, Teppei (2014). Causal Inference in Conjoint Analysis: Understanding Multidimensional Choices via Stated Preference Experiments. Political Analysis, 22(1), 1-30.

Hainmueller, Jens, Hangartner, Dominik, \& Yamamoto, Teppei (2015). Validating Vignette and Conjoint Survey Experiments against Real-World Behavior. Proceedings of the National Academy of Science, 112(8), 2395-400.

Karreth, Johannes, Polk, Jonathan T., \& Allen, Christopher S. (2013). Catch-all or Catch and Release? The Electoral Consequences of Social Democratic Parties' March to the Middle in Western Europe. Comparative Political Studies, 46(7), 791-822.

Katz, Richard S., \& Mair, Peter (1995). Changing Models of Party Organization and Party Democracy: The Emergence of the Cartel Party. Party Politics, 1(1), 5-28.

Katz, Richard S., \& Mair, Peter (2009). The Cartel Party Thesis: A Restatement. Perspectives on Politics, 7(4), 753-766.

Katz, Richard S., \& Mair, Peter (2018). Democracy and the Cartelization of Political Parties. Oxford: Oxford University Press.

Keman, Hans (2011). Third Ways and Social Democracy: The Right Way to Go? British Journal of Political Science, 41(3), 671-680.

Kirchheimer, Otto (1966). The Transformation of the Western European Party System. In Joseph LaPalombara \& Myron Weiner (Eds.), Political Parties and Political Development (pp. 177-200). Princeton: Princeton University Press.

Krosnick, Jon (1999). Survey Research. Annual Review of Psychology, 50: 537-67.

Krouwel, André (2003). Otto Kirchheimer and the Catch-All Party. West European Politics, 26(2), 23-40.

Lipset, Seymour M. (1964). The Changing Class Structure and Contemporary European Politics. Daedalus, 93(1), 290-299. 
Marx, Paul, \& Nguyen, Christoph (2018). Anti-Elite Parties and Political Inequality: How Challenges to the Political Mainstream Reduce Income Gaps in Internal Efficacy. European Journal of Political Research, 57(4), 919-940.

Merrill, Samuel, \& Grofman, Bernhard (1997). Directional and Proximity Models of Voter Utility and Choice: A New Synthesis and an Illustrative Test of Competing Models. Journal of Theoretical Politics, 9(1), 25-48.

Miratrix, Luke W., Jasjeet S. Sekhon, Alexander G. Theodoridis, and Luis F. Campos (2018). Worth Weighting? How to Think About and Use Weights in Survey Experiments. Political Analysis, 26(3), 275-291.

Moffitt, Benjamin, \& Tormey, Simon (2014). Rethinking Populism: Politics, Mediatisation and Political Style. Political Studies, 62(2), 381-397.

Nannestad, Peter and Martin Paldam (1994). The VP function: A Survey of the Literature on Vote and Popularity Functions after 25 Years. Public Choice, 79(2), 213-45.

Oliver, J. Eric, \& Rahn, Wendy M. (2016). Rise of the Trumpenvolk: Populism in the 2016 Election. Annals of the American Academy of Political and Social Science, 667(1), 189-206.

Pardos-Prado, Sergio (2012). Valence Beyond Consensus: Party Competence and Policy Dispersion from a Comparative Perspective. Electoral Studies, 31(2), 342-352.

Quinn, Tom (2008). The Conservative Party and the "Centre Ground" of British Politics. Journal of Elections, Public Opinion and Parties, 18(2), 179-199.

Rabinowitz, George, \& Stuart E. Macdonald (1989). A Directional Theory of Issue Voting. American Political Science Review, 83(1), 93-121.

Sanders, David (1999). Conservative Incompetence, Labour Responsibility and the Feelgood Factor: Why the Economy Failed to Save the Conservatives in 1997. Electoral Studies, 18(2), 251-270. 
Sanders, David, Clarke, Harold D., Stewart, Marianne C., \& Whiteley, Paul (2011). Downs, Stokes and the Dynamics of Electoral Choice. British Journal of Political Science, 41(2), 287.

Schofield, Norman (2004). Equilibrium in the Spatial 'Valence' Model of Politics. Journal of Theoretical Politics, 16(4), 447-481.

Schofield, Norman, \& Sened, Itai (2005). Modeling the Interaction of Parties, Activists and Voters: Why Is the Political Center So Empty? European Journal of Political Research, 44(3), 355-390. Serra, Gilles (2010). Polarization of What? A Model of Elections with Endogenous Valence. Journal of Politics, 72(2), 426-437.

Somer-Topcu, Zeynep (2007). Party Policy Strategies and Valence Issues: An Empirical Study of Ten Post-Communist European Party Systems. Paper presented at the Conference on the Dynamics of Party Position Taking, SUNY Binghamton, available at http://citeseerx.ist.psu.edu/viewdoc/download?doi=10.1.1.489.9028\&rep=rep1\&type=pdf [last accessed 21 May 2019].

Stone, Walter J., \& Simas, Elizabeth N. (2010). Candidate Valence and Ideological Positions in US House Elections. American Journal of Political Science, 54(2), 371-388.

Strøm, Kaare (1990). A Behavioral Theory of Competitive Political Parties. American Journal of Political Science, 34(2), 565-598.

Stubager, Rune (2018). What Is Issue Ownership and How Should We Measure It? Political Behavior, 40 (2), 345-370.

Stubager, Rune, \& Slothuus, Rune (2013). What Are the Sources of Political Parties' Issue Ownership? Testing Four Explanations at the Individual Level. Political Behavior, 35(3), 567588.

Tomz, Michael, \& Van Houweling, Robert P. (2010). Candidate Repositioning. Unpublished manuscript, available at https://web.stanford.edu/ tomz/working/TomzVanHouwelingRepositioning-2010-02-02.pdf [last accessed 21 May 2019]. 
Vannatta, Seth (2014). Conservatism and Pragmatism: In Law, Politics, and Ethics. Basingstoke: Palgrave Macmillan.

Vegetti, Federico (2014). From Political Conflict to Partisan Evaluations: How Citizens Assess Party Ideology and Competence in Polarized Elections. Electoral Studies, 35(September), 230-241.

Vivyan, Nick, \& Wagner, Markus (2015). What Do Voters Want from Their Local MP? The Political Quarterly, 86(1), 33-40.

Vivyan, Nick, \& Wagner, Markus (2016). House or Home? Constituent Preferences Over Legislator Effort Allocation. European Journal of Political Research, 55(1), 81-99.

Wagner, Markus, \& Zeglovits, Eva (2014). Survey Questions about Party Competence: Insights from Cognitive Interviews. Electoral Studies, 34, 280-90.

Walgrave, Stefaan, van Camp, Kirsten, Lefevere, Jonas, \& Tresch, Anke (2016). Measuring Issue Ownership with Survey Questions. A Question Wording Experiment. Electoral Studies, 42, 290299.

Walgrave, Stefaan, Tresch, Anke \& Lefevere, Jonas (2015). The Conceptualisation and Measurement of Issue Ownership. West European Politics, 38(4), 778-796.

Zakharova, Maria, \& Warwick, Paul V. (2014). The Sources of Valence Judgments: The Role of Policy Distance and the Structure of the Left-Right Spectrum. Comparative Political Studies, 47(14) 2000-2025. 
Figure 1. Illustration of conjoint experimental design

First, here are descriptions of two political parties.

Please read them both carefully, and then indicate below which of the two parties you think would be generally the most competent, regardless of how much you might agree with each party.

\begin{tabular}{|c|c|c|}
\hline & Party A & Party B \\
\hline Average share in recent polls & $40 \%$ & $25 \%$ \\
\hline Leader name & Daniel Cope & Hazel Berry \\
\hline Top issue priority & Education & Healthcare \\
\hline When last in government & Never & Fairly recently \\
\hline Political outlook & Very left wing & Very right wing \\
\hline \multirow{4}{*}{$\begin{array}{l}\text { How the party appears } \\
\text { Size of the party membership } \\
\text { ong the party has been around }\end{array}$} & Largely united & Somewhat divided \\
\hline & Large & Medium \\
\hline & For some time & For many decades \\
\hline & Most competent & Most competent \\
\hline
\end{tabular}

Could you rate both on the following scale from 0 (not at all competent) to 6 (very competent)?

$\begin{array}{cllllll}\begin{array}{c}0 \text { - not at all } \\ \text { competent }\end{array} & 1 & 2 & 3 & 4 & 5 & \begin{array}{c}6-\text { very } \\ \text { competent }\end{array} \\ \end{array}$

Party A

Party B 
Figure 2. Effects of party characteristics on general competence (Profile Choice): Estimates and $95 \%$ confidence intervals ( $N=6608$ observations, 1652 respondents).

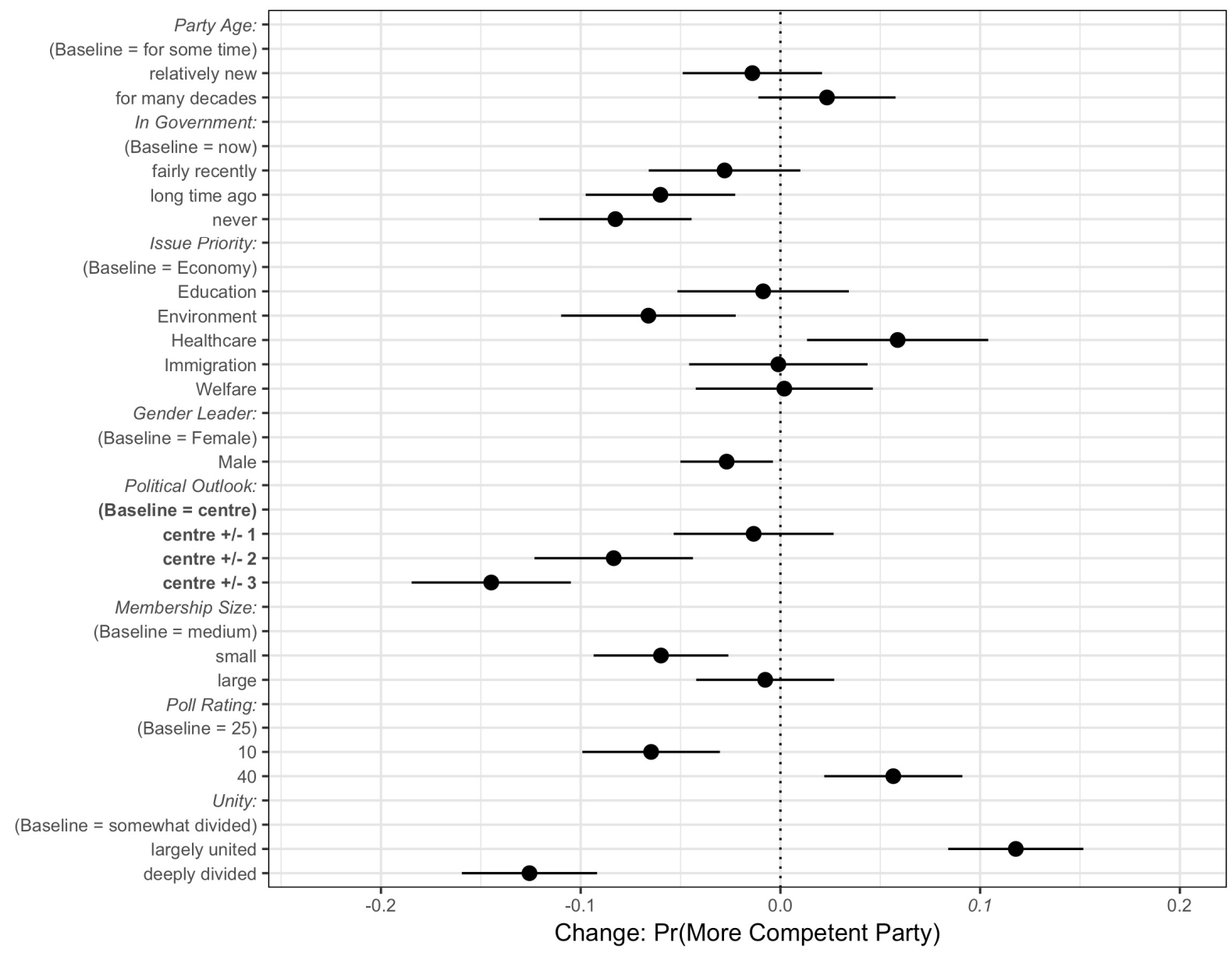


Table 1. Effects of political outlook attribute on general competence (Profile Choice).

Note: Estimates are based on full model. $\mathrm{N}$ (observations) $=6608 ; \mathrm{n}$ (respondents) $=1652$

\begin{tabular}{|l|r|r|r|}
\hline & Estimate & s. e. & $\operatorname{Pr}(<|z|)$ \\
\hline Base = Centre \\
\hline Centre +/- 1 & -0.01 & 0.02 & 0.512 \\
\hline Centre $+/-2$ & -0.08 & 0.02 & 0.000 \\
\hline Centre $+/-3$ & -0.15 & 0.02 & 0.000 \\
\hline
\end{tabular}


Figure 3. Effects of party characteristics on willingness to compromise, realism and complexity: Estimates and $95 \%$ confidence intervals ( $N=6608$ observations, 1652 respondents).

Note: Baseline is 'centre'.

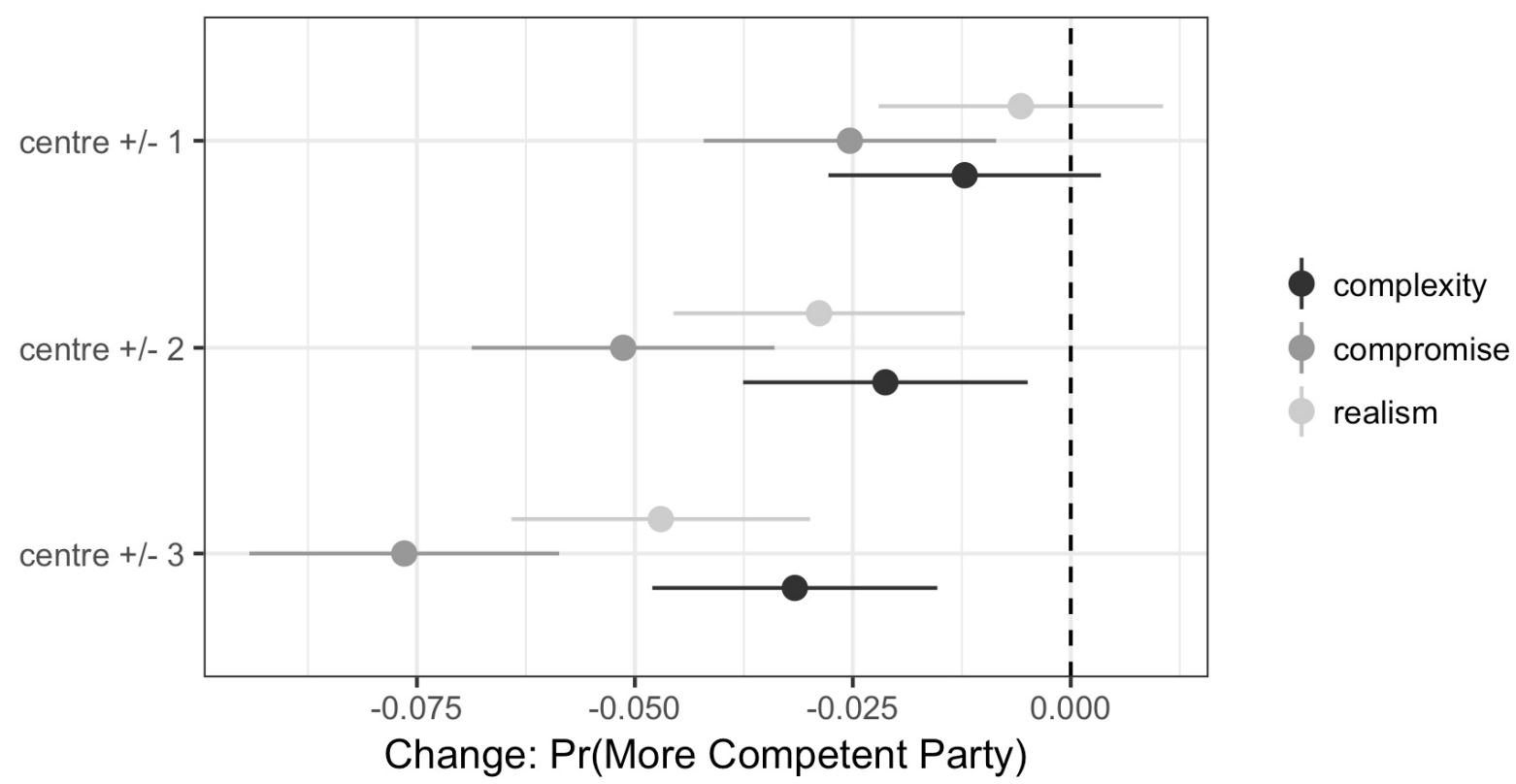


Table 2. Effects of political outlook attribute on ratings of compromise, realism, and complexity.

Note: $\mathrm{N}$ (observations) $=6608 ; \mathrm{n}$ (respondents) $=1652$

\begin{tabular}{|l|r|l|l|l|l|l|l|l|r|}
\hline & \multicolumn{4}{|l|}{ Compromise } & \multicolumn{3}{l|}{ Realism } & \multicolumn{3}{l|}{ Complexity } \\
\hline & Estimate & s.e. & $\operatorname{Pr}(<|\mathrm{z}|)$ & Estimate & s.e. & $\operatorname{Pr}(<|\mathrm{z}|)$ & Estimate & s.e. & $\operatorname{Pr}(<|\mathrm{z}|)$ \\
\hline Base = Centre & & & & & & & & & \\
\hline Centre +/- 1 & -0.03 & 0.01 & 0.003 & -0.01 & 0.01 & 0.491 & -0.01 & 0.01 & 0.127 \\
\hline Centre +/- 2 & -0.05 & 0.01 & 0.000 & -0.03 & 0.01 & 0.001 & -0.02 & 0.01 & 0.011 \\
\hline Centre +/- 3 & -0.08 & 0.01 & 0.000 & -0.05 & 0.01 & 0.000 & -0.03 & 0.01 & 0.000 \\
\hline
\end{tabular}


Figure 4. Effects of parties' positions on competence (Profile Choice): Estimates and 95\% confidence intervals for respondents at each location on the left-right scale.

A

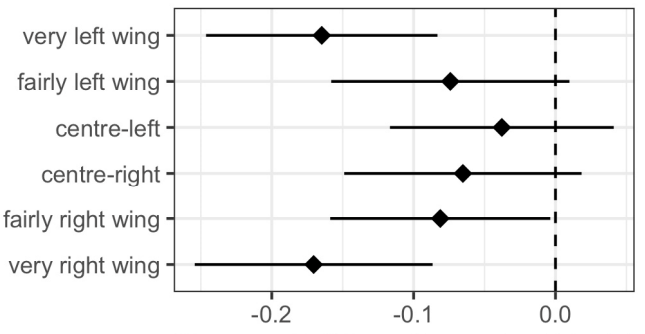

Change: $\operatorname{Pr}$ (More Competent Party)

C

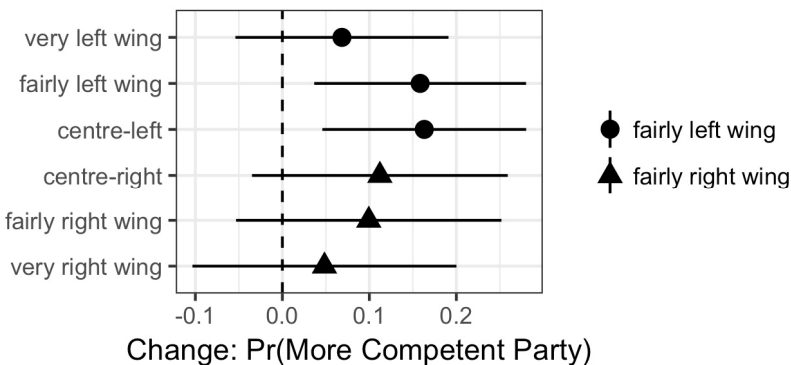

B

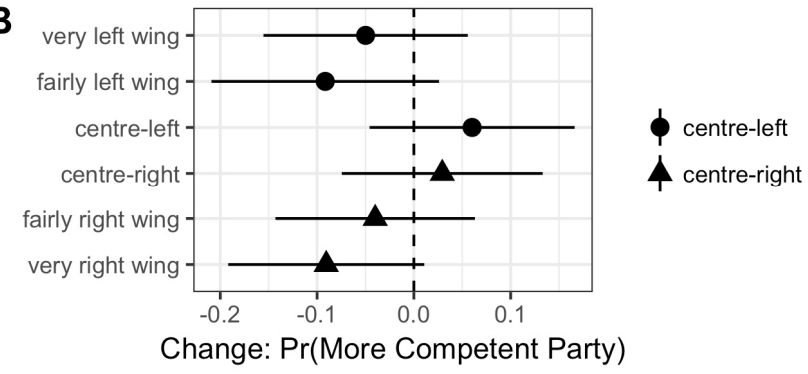

D

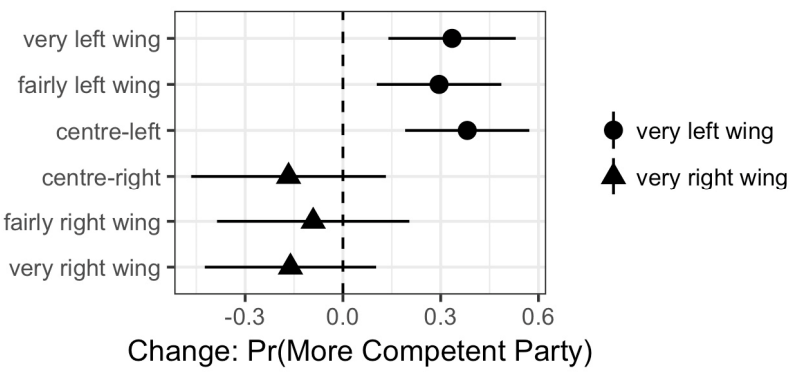




\title{
Moderation and competence: \\ How a party's ideological position shapes its valence reputation
}

\author{
- Supplementary online appendix -
}

\section{Table of contents}

1. Table A1: Full list of attributes randomly assigned to party profile tables. 2

2. Figure A1: Effects of party characteristics on competence (Profile Rating) 4

3. Figure A2: Interaction with level of certainty about meaning of left-right 4

4. Figure A3: Main results with full ideological scale 5

5. Full questionnaire 6 
Table A1. Full list of attributes randomly assigned to party profile tables.

\begin{tabular}{|c|c|}
\hline List 1: Average share in recent polls & $\begin{array}{l}40 \% \\
25 \% \\
10 \% \\
\end{array}$ \\
\hline List 2: Leader name & $\begin{array}{l}\text { Simona Duke } \\
\text { Rebecca Rimmington } \\
\text { Katrina Small } \\
\text { Ailsa Thorne } \\
\text { Clara Matthews } \\
\text { Rachel Carroll } \\
\text { Vicky Randolph } \\
\text { Suzannah Wills } \\
\text { Lily Merrill } \\
\text { Sarah Higgins } \\
\text { Anne-Marie Lacey } \\
\text { Eleanor Jones } \\
\text { Susannah Fry } \\
\text { Tessa Leonard } \\
\text { Juliet Martin } \\
\text { Monica Austin } \\
\text { Hazel Berry } \\
\text { Diana Hartley } \\
\text { Rose Dudley } \\
\text { Kathy Clifford } \\
\text { Damian Bevan } \\
\text { Christian Booth } \\
\text { Daniel Cope } \\
\text { Max Atherton } \\
\text { Alex Marley } \\
\text { Owen Morley } \\
\text { James Lang } \\
\text { Matthew Robins } \\
\text { Alec Johns } \\
\text { Antony Mays } \\
\text { Paul Draper } \\
\text { Michael Bone } \\
\text { lan Salter } \\
\text { Glenn Singleton } \\
\text { Joseph Plummer } \\
\text { Nicholas Phillips } \\
\text { John Hawkins } \\
\text { Robert Tucker } \\
\text { George Milner } \\
\text { Graeme Davies }\end{array}$ \\
\hline List 3: Top issue priority & $\begin{array}{l}\text { Education } \\
\text { Economy } \\
\text { Environment } \\
\text { Immigration } \\
\text { Healthcare } \\
\text { Welfare }\end{array}$ \\
\hline List 4: When last in government & In government now \\
\hline
\end{tabular}




\begin{tabular}{|l|l|}
\hline & Fairly recently \\
& A long time ago \\
& Never \\
\hline List 5: Political outlook & Very left wing \\
& Fairly left wing \\
& Centre left \\
& Centre \\
& Centre right \\
& Fairly right wing \\
& Very right wing \\
\hline List 6: How the party appears & Largely united \\
& Somewhat divided \\
\hline List 7: Size of the party membership & Deeply divided \\
\hline List 8: How long the party has been around & Small \\
& Medium \\
& Large \\
\hline
\end{tabular}


Figure A1. Effects of party characteristics on competence (Profile Rating): Estimates and 95\% confidence intervals.

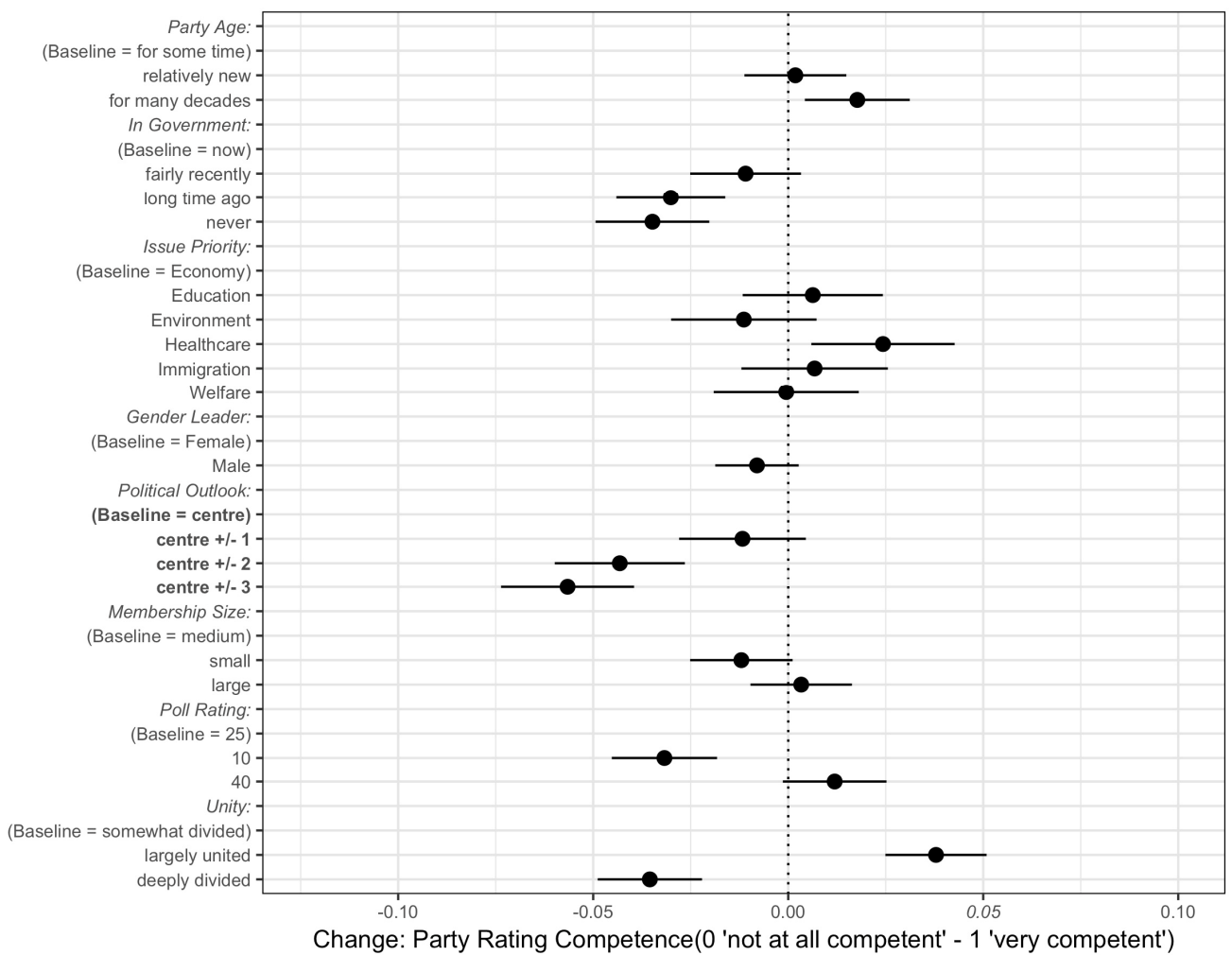

Figure A2. Effects of party characteristics on competence, interacted with level of certainty about meaning of 'left' and 'right' (split at median): Estimates and $95 \%$ confidence intervals.
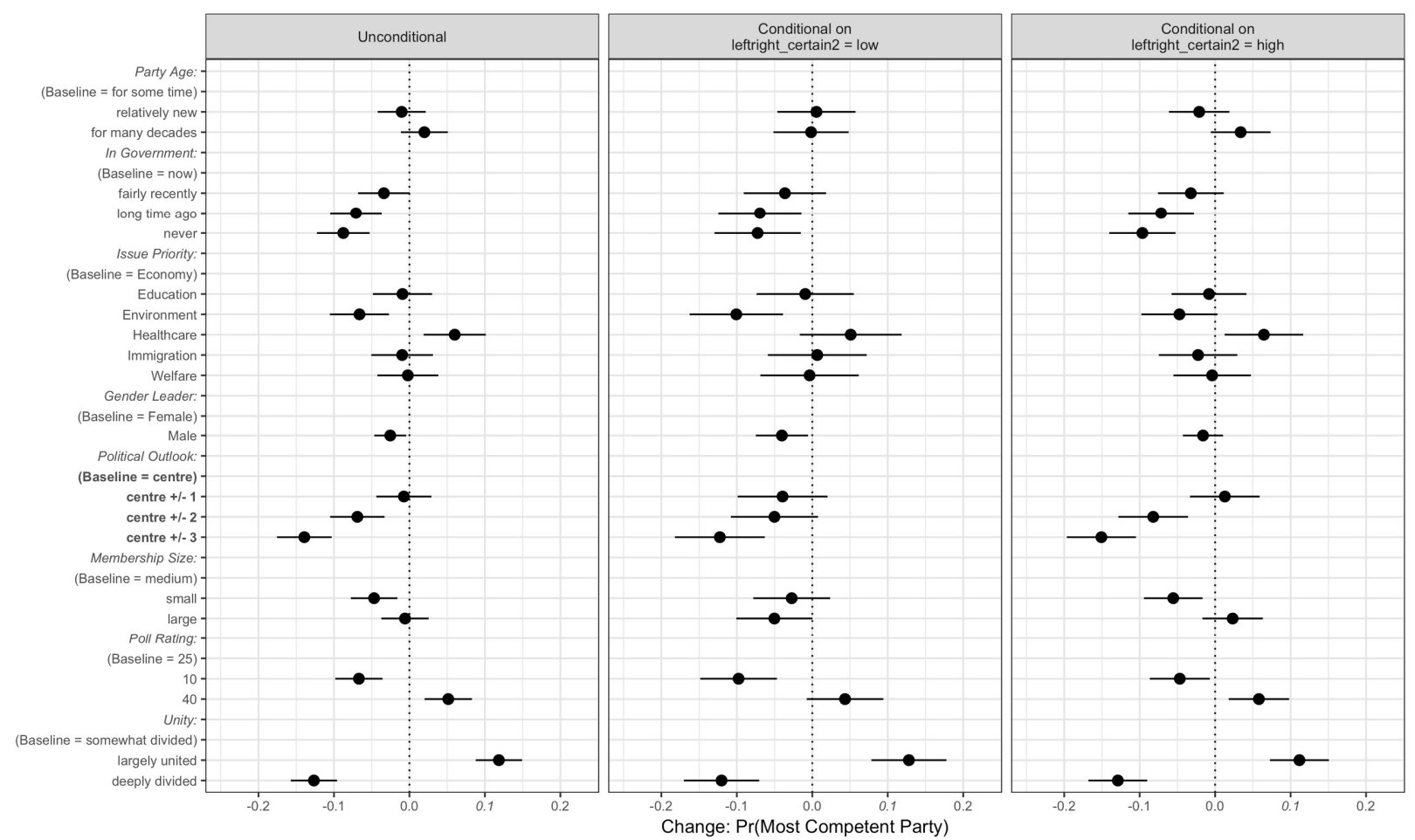
Figure A3. Main results with full ideological scale: Estimates and $95 \%$ confidence intervals.

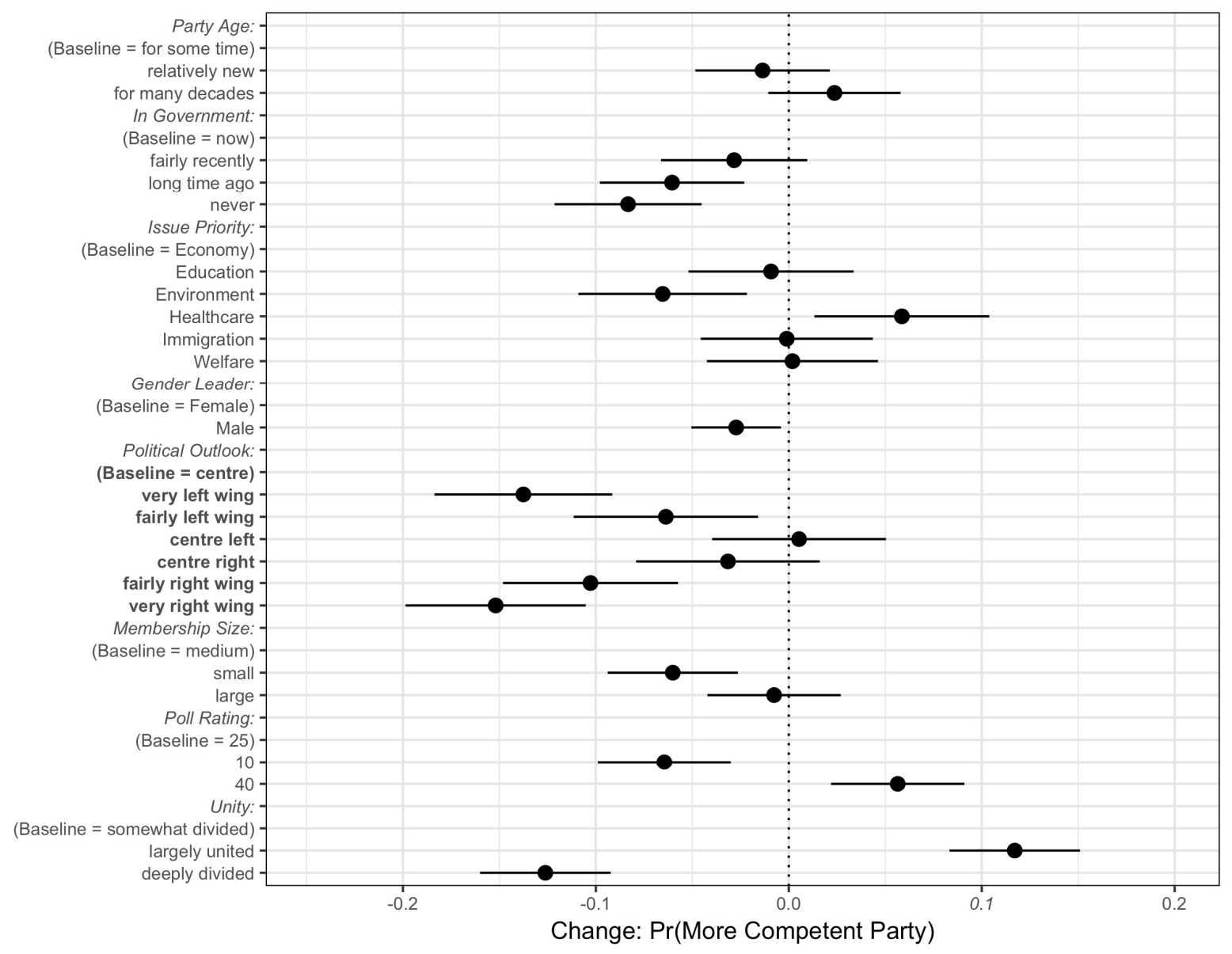




\section{Full survey questionnaire}

\section{[Choice task 1]}

First, here are descriptions of two political parties.

Please read them both carefully, and then indicate below which of the two parties you think would be generally the most competent, regardless of how much you might agree with each party.

\begin{tabular}{|l|l|l|}
\hline & Party A & Party B \\
\hline Average share in recent polls & {$[$ randomised from List 1] } & {$[$ randomised from List 1] } \\
\hline Leader & {$[$ randomised from List 2] } & {$[$ randomised from List 2] } \\
\hline Top issue priority & {$[$ randomised from List 3 $]$} & {$[$ randomised from List 3] } \\
\hline When last in government & {$[$ randomised from List 4 $]$} & {$[$ randomised from List 4] } \\
\hline Political outlook & {$[$ randomised from List 5] } & {$[$ randomised from List 5] } \\
\hline How the party appears & {$[$ randomised from List 6] } & {$[$ randomised from List 6] } \\
\hline Size of the party membership & {$[$ randomised from List 7] } & {$[$ randomised from List 7] } \\
\hline How long the party has been around & {$[$ randomised from List 8] } & {$[$ randomised from List 8] } \\
\hline
\end{tabular}

Q1. Which party do you think would be the most competent?

$<1>$ Party A

$<2>$ Party B

Q2. Could you rate both on the following scale from 0 (not at all competent) to 6 (very competent)?

[Grid with two options to be rated on slider from 0 - Not at all competent to 6 - Very competent]

a. Party A

Q3. Next, here are three more scales on which we'd like you to guess how Party A and Party B would rate.

Some parties are unwilling to compromise, believing that they should stick to their principles. Others are more willing, believing that co-operation and compromise are sometimes necessary to get things done. How would you rate the two parties on this scale of willingness to compromise?

[Grid with two options to be rated on slider from 0 - Not at all willing to 6 - Very willing]

a. Party A

b. Party B

Q4. Next, please say how realistic you think each party would be about what can and cannot be achieved?

[Grid with two options to be rated on slider from 0 - Not at all realistic to 6 - Very realistic]
a. Party $A$
b. Party B

Q5. Some parties put forward simple solutions to problems, while others think that things are more complicated. How would you rate the likely approaches and proposals of the two parties on this scale? 

a. Party $A$
b. Party B

\section{[Choice task 2]}

Now, here are two more descriptions of two political parties. Again, please read them both carefully, and then indicate below which of the two parties you think would be generally the most competent, regardless of how much you might agree with each party.

\begin{tabular}{|c|c|c|}
\hline & Party C & Party D \\
\hline Average share in recent polls & [randomised from List 1] & [randomised from List 1] \\
\hline Leader & [randomised from List 2] & [randomised from List 2] \\
\hline Top issue priority & [randomised from List 3] & [randomised from List 3] \\
\hline When last in government & [randomised from List 4] & [randomised from List 4] \\
\hline Political outlook & [randomised from List 5] & [randomised from List 5] \\
\hline How the party appears & [randomised from List 6] & [randomised from List 6] \\
\hline Size of the party membership & [randomised from List 7] & [randomised from List 7] \\
\hline How long the party has been around & [randomised from List 8] & [randomised from List 8] \\
\hline
\end{tabular}

Q6. Which party do you think would be the most competent?

$<1>$ Party C

$<2>$ Party D

Q7. Could you rate both on the following scale from 0 (not at all competent) to 6 (very competent)? [Grid with two options to be rated on slider from 0 - Not at all competent to 6 - Very competent]
a. Party C
b. Party D

Q8. Next, here are the same three scales on which we'd like you to rate Party C and D.

How would you rate each in terms of how willing they would be to compromise?

[Grid with two options to be rated on slider from 0 - Not at all willing to 6 - Very willing]
a. Party C
b. Party D

Q9. Next, how realistic do you think each party would be about what can and cannot be achieved? [Grid with two options to be rated on slider from 0 - Not at all realistic to 6 - Very realistic]
a. Party C
b. Party D

Q10. In terms of the simplicity or complexity of their proposals, how would you rate the likely approaches of the two parties?

[Grid with two options to be rated on slider from 0 - Very simple to 6 - Very complex]
a. Party C
b. Party D 
Q11a. Finally, a few questions about you. Some people think of themselves as usually being a supporter of one political party rather than another. Do you usually think of yourself as being a supporter of one particular party or not?

$<1>$ Yes

$<2>$ No

\section{[If No is selected, then skip to Q12]}

Q11b. Which party is that?

$<1>$ Conservative

$<2>$ Labour

$<3>$ Liberal Democrat

$<4>$ UK Independence Party

$<5>$ Green Party

$<6>$ [if Scotland==1] SNP

$<7>$ [if Wales $==1$ ] Plaid Cymru

$<8>$ Other [please specify:

Q11c. How strongly would you say that you support that party?

$<1>$ Very strongly

$<2>$ Fairly strongly

$<3>$ Not very strongly

Q12a. In politics, people often speak of left and right. Where would you place yourself on the following scale?

$<1>$ Very left wing

$<2>$ Fairly left wing

$<3>$ Centre left

$<4>$ Centre

$<5>$ Centre right

$<6>$ Fairly right wing

$<7>$ Very right wing

$<99>$ Don't know

Q12b. Some people use the terms 'left' and 'right' very often and understand them well. Others are a bit less sure about the meaning of left and right. How sure are you about what left and right mean in politics?

[Slider from 0 - Very unsure to 6 - Very sure]

Q13. What do you think is the most important problem facing this country today? 